\title{
Retracted Article: Overexpression of the Arabidopsis ASYMMERTIC LEAVES2-LIKE11 gene in Cockscomb leads to modification of flowering and lateral branching
}

\author{
Xu-Dong Sun • Lai-Sheng Meng • Guang-Chao Wang • \\ Ying Zhou $\cdot$ Zhen-hua Feng
}

Received: 26 October 2009/Accepted: 10 March 2010/Published online: 26 March 2010

(C) Springer Science+Business Media B.V. 2010

The article was published Online First, but is retracted due to disputed authorship and severe omissions in the information of collaborators about the publication.

X.-D. Sun · G.-C. Wang · Y. Zhou · Z. Feng

School of Life Science and Technology, Tongji University,

200092 Shanghai, China

X.-D. Sun

Institut de recherché en biologie végétale, Département de sciences biologiques, Université de Montréal, Montreal, QC

4101, Canada

L.-S. Meng $(\bowtie)$

South China Botanical Garden, Chinese Academy of Sciences,

510650 Guangzhou, China

e-mail: menglsh2010@yahoo.com.cn 